CREAT. MATH. INFORM.

Volume 29 (2020), No. 2,

Pages $237-242$
Online version at https : //creative-mathematics. cunbm. utcluj.ro/

Print Edition: ISSN 1584 - 286X; Online Edition: ISSN 1843 - 441X

DOI: https://doi.org/10.37193/CMI.2020.02.15

\title{
The Cartan connection: sketches for a portrait of Kentaro Yano
}

\author{
BOGDAN D. SUCEAVĂ
}

\begin{abstract}
We are describing the historical context in which Kentaro Yano prepared his doctoral dissertation under Élie Cartan's coordination, and how this work was published in Romania, with Analele Ştiinţifice ale Universităţii "Al. I. Cuza". We describe some of the many encounters made possible by Élie Cartan's extraordinary creative contributions, which lead to a series of important collaborations, some of them of lasting impact until today.
\end{abstract}

In Kentaro Yano's biography [29] the information on his doctoral dissertation is not included, and no information on its actual publication is given. According to Leopold Verstraelen [32], Radu Roşca recalled that there was a pre-WW II connection between Kentaro Yano's doctoral thesis and the Romanian academic environment. Since several resources about Kentaro Yano's biography do not incorporate this information, we hereby complement this important reference, which should be viewed in the historical context pertaining to the period 1936-1939. The few elements we hereby describe have all to do with the extraordinary impact of Élie Cartan's work and inspiring presence in the mathematical environment in the 1930s; in a certain way, the present note could be viewed as a complement to the comprehensive monograph [2], to support the assertion that Élie Cartan's work raised major attention and brought together mathematicians from many traditions, contributing essentially to international communication and collaboration.

In June 1938, Kentaro Yano defended at the University of Paris his doctoral dissertation titled Les espaces à connexion projective et la géométrie projective des "path", with Élie Cartan as doctoral adviser and G. Valiron and G. Darmois as committee members [34]. It was the culmination of two years of intensive study under Cartan's guidance. The actual thesis is published as [35]. The fact that this is the actual doctoral thesis is also confirmed in [28], at p. xxxvi.

As the articles bear the mark of the original printing outlet, we can see that the original work was printed with Presa Bună, a facility established by the Catholic Diocese in Iaşi in October 1926, where at that time existed the technical ability to print mathematical fonts.

According to his autobiography, Kentaro Yano left Paris in 1938, and in Japan defended a second doctoral thesis [36]. It is quite possible that the administrative environment in Japan at that time made this choice necessary.

Élie Cartan had many connections in the Romanian mathematical circles, starting with Gheorghe Tiţeica (1873-1939), who was [1], like Cartan himself, a former doctoral student of Gaston Darboux (1872-1917). Tițeica and Cartan have not been classmates, but it is very likely they met in Paris before 1899. According to [2], p.6, Élie Cartan graduated from l'École Normale Superieure in 1891, then served in the army, and subsequently worked on his doctoral thesis for two years, 1892-1894, in Paris. Between 1894 and 1896, Cartan was a lecturer at the University of Montpellier, and between 1896 and 1903 was a

Received: 10.09.2020. In revised form: 15.09.2020. Accepted: 22.09.2020

1991 Mathematics Subject Classification. 01A27, 01A60, 01A70, 01 A72.

Key words and phrases. Kentaro Yano, Élie Cartan. 


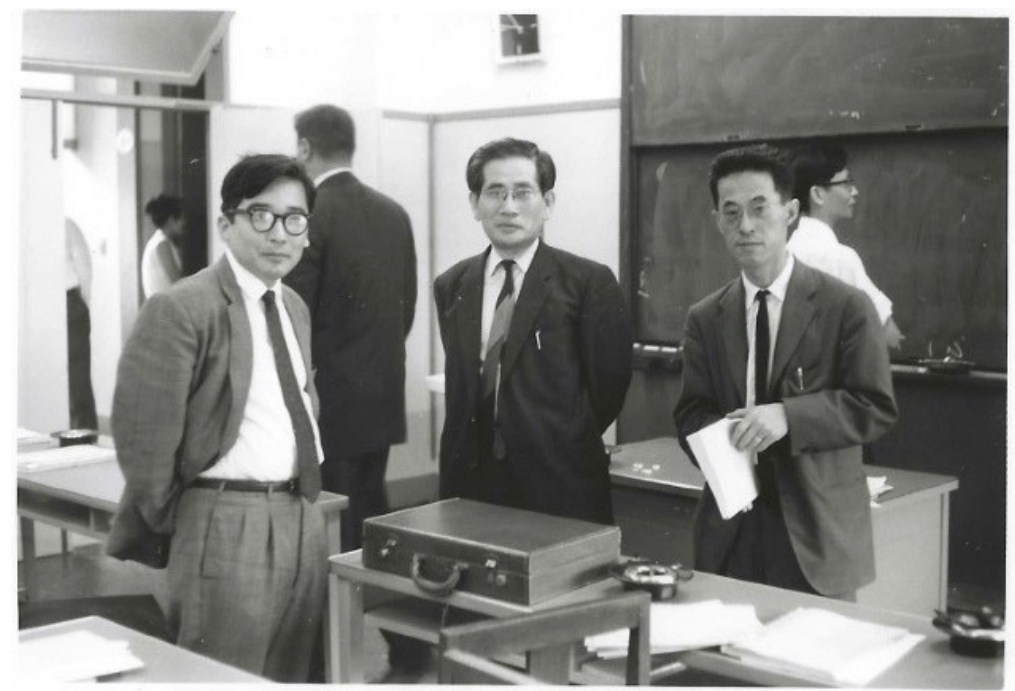

FIGURE 1. In this image, Tadashi Nagano (left, a former doctoral student of Kentaro Yano), Kentaro Yano (center), and Katsumi Nomizu (right). Photo from Tadashi Nagano's family archive, reprinted with Reiko Nagano's permission.

lecturer at the Faculty of Sciences of the University of Lyon [2], p.7. Tुiţeica was in Paris between the fall of 1896 and the summer of 1899, when he returned to Bucharest [1]. Cartan met with Titseica several times, at the International Congresses of Mathematicians in 1920 (Strasbourg), 1924 (Bologna), 1932 (Zürich), and 1936 (Oslo). Over the years, Cartan had an extended communications with several Romanian mathematicians, out of which there is published his correspondence with Ţiţeica, Alexandru Pantazi (1873-1939), and Gheorghe Vrănceanu (1900-1979) [9], fact mentioned in [2], p. 28. Akivis and Rosenfeld describe in [2], p. 28: "In April and May of 1931 Cartan made a trip to Romania and Poland. In Romania he delivered a series of lectures in Cluj, Bucharest, Iaşi (Yassy), and Cernăuţi (Chernovcy, after WW II in U.S.S.R., [ and thereafter in Ukraine]). In the same year, Cartan was elected an honorary member of the Romanian Academy of Sciences in Bucharest."

There is an outstanding testimony of the encounter in Bucharest, where Cartan's visit coincided with a meeting of the local mathematical society, Societatea de Matematică (established in 1909, today continued by a society in partnership with the American Mathematican Society). The witness of Cartan's presence in Bucharest was nobody else but Dan Barbilian (1895-1961), see e.g.[7], who writes in a note published only after his death the following description, [3], p. 171.

In the meeting of the Society of Mathematics from May 1931, Élie Cartan presented a talk on the geometry of the isotropic curves and manifolds. At the end, Gh. Țiţeica referred to his "5-lei problem", for the first time called so in public, and about its first solution I gave, but with some formal simplifications brought to it in the meantime.

I was a sort of ad-hoc secretary of that particular meeting. I just found recently the notes I took at that time. Ţiţeica, this man full of intuition, 
asked the question whether on the sphere or on other surfaces the "5-lei configuration" holds true (that is, of equiradial geodesic circles).

However, Tițeica's question makes sense only on surfaces with constant curvature. It is there, on a very small patch on that surface, the geodesic circles (the locus of the points equidistant on the surface [Barbilian's underlining] from a fixed point; the path minimizer between two given points, thus the arc of geodesic passing by there) cuts two by two and the construction is unequivocal.

Thus, the construction makes sense only on the so-called symmetrizable surfaces introduced in Geometry by Élie Cartan himself.

Based on this first-hand testimonial, we see that the conversations that took place around Cartan's talk had to do with symmetric spaces, as Cartan was reflecting at that time on this new concept [8]. It is possible that in the audience were, besides Țiţeica, Dimitrie Pompeiu, Simeon Stoilow, Gheorghe Vrănceanu, and other first class mathematicians. The "5-lei problem" is what we call today the Tzitzeica-Johnson configuration, see e.g. [5]. What is particularly remarkable is that in this encounter we see ideas pertaining today to comparison geometry, and that this conversation took place before Topogonov's theorem was established [31]. For the origins of the important idea of triangle comparison, see the thorough historical account in [30], and for the use of Tzitzeica-Johnson configuration as criterion, see [6].

Cartan's visit in Romania was full of substantive academic encounters. In Iaşi, the mathematical community benefitted from the expertise of the excellent geometer Alexandru Myller, and it is very likely that Cartan was received as warmly as in Bucharest. It is therefore conceivable that Kentaro Yano's 1938 doctoral dissertation was welcomed with great interest by an academic environment fully connected to Cartan's mathematical ideas. Thus, the publication of [35] was yet one more time a reaffirmation of an important academic connection that could be traced four decades back, since the 1890s.

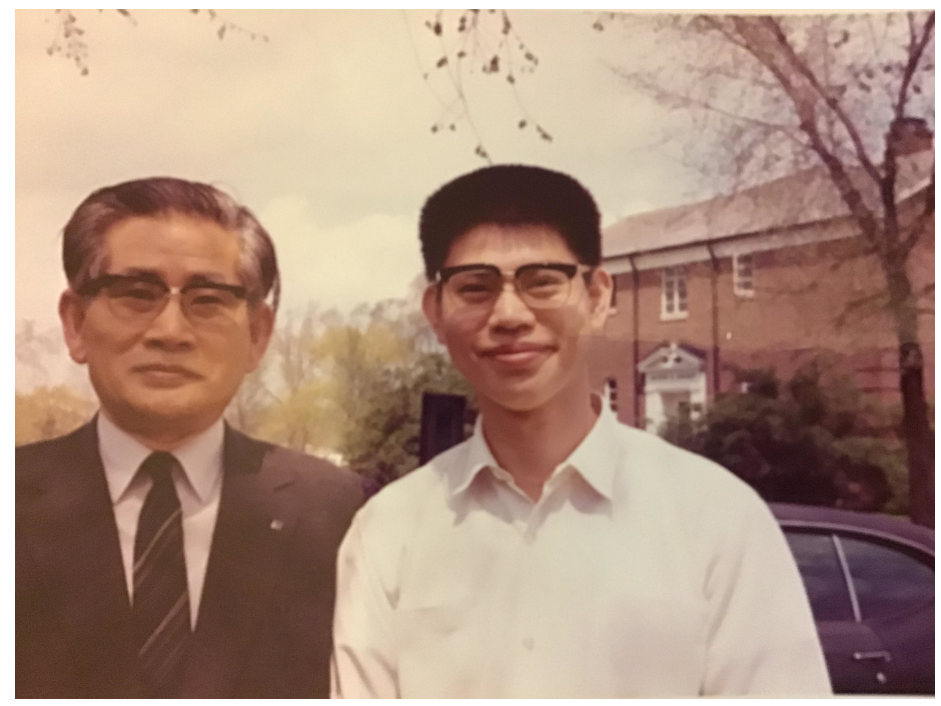

FIGURE 2. Kentaro Yano and Bang-Yen Chen, in East Lansing, MI, on May 14, 1972. Photo reprinted with the generous permission of Dr. BangYen Chen. 
After 1938, Kentaro Yano worked at the Tokyo Institute of Technology. As it is pointed out in [29], "He remained on the staff at the Institute for the whole of his career but made many trips abroad and spent long periods in other universities." After WW II, Kentaro Yano became widely known, mainly due to his monographs [37, 38, 39], to mention here just a few of his very influential works. As visiting professor to Princeton, he wrote with Salomon Bochner [4], a reference still of interest today. Besides this collaboration, Kentaro Yano developed very successful collaborations with other authors, most notably with Shigeru Ishihara and Masahiro Kon.

Kentaro Yano's academic prestige and influence was extremely important. To cite one notable example, Sh. Kobayashi mentions in his foreword of the work [26], published first in Japanese in 1977, and translated into English only recently, that: "I would like to thank my former teacher, Professor Kentano Yano, who suggested me to write this book and has advised me over many years."

An outstanding research relationship developed between Kentaro Yano and Bang-Yen Chen, who describes in [10], in stellar terms their very fruitful collaboration.

I met Professor Kentaro Yano for the first time in late 1970 at Michigan State University while he was a visiting professor under the invitation of Professors D. E. Blair and G. D. Ludden. Since then he had visited MSU as visiting professor for a few times until 1973; about one month for each visit. During his visits at MSU, we had many discussions on geometry of conformally flat manifolds and submanifolds, among others. Usually, we discussed after lunch until 5 pm almost every week day. Hence many of our joint articles done during that period are related to conformally flat manifolds and submanifolds [15, 16, 17, 18, 40]. From his visits at MSU we also published several articles on integral formulas and pseudoumbilical or quasi-umbilical submanifolds (see [11, 12, 13, 14, 20, 21, 22, 23]). Later, we published two joint articles [24, 25] on different subjects via communications by air mails.

From his visits at MSU, I learned very much from him. Most importantly, I tried to learn from his skill as well as from his philosophy on research. Consequently, Professor Yano had very important impact on my research as well.

In many ways, this was over many decades a very seminal heritage coming from a common academic tradition, doubled by many direct encounters and many personal conversations.

The journal in Iaşi published over the years several important papers; most notable is the publication in 1965 of T.J. Willmore's paper [33] in which the famous Willmore conjecture was first stated. Since then, the conjecture was solved in 2014 in [27].

The author of the present note expresses his thanks to Dr. Mihai Anastasiei and to Dr. Nicoleta Dabija, who helped him clarify a few historical facts related to the academic and editorial environment in Iaşi in the 1930s, and as well to Dr. Leopold Verstraelen, for his encouragement to pursue this historical investigation [32].

\section{REFERENCES}

[1] Agnew, A. F., Bobe, A., Boskoff, W. G. and Suceavă, B. D., Gheorghe Ţiţeica and the origins of affine differential geometry, Historia Math., 36 (2009), No. 2, pp. 161-170

[2] Akivis, M. A. and Rosenfeld, B. A., Élie Cartan, (1869-1951), Translated by V.V. Goldberg, translation edited by Simeon Ivanov, Translations of Mathematical Monographs, Volume 123, Amer. Math. Soc., Providence, RI, 1993 
[3] Barbilian, D., Pagini inedite, volumulm II., Editors Gerda Barbilian and Viorel Gh. Vodă, Editura Albatros, Bucharest (1984)

[4] Bochner, S. and Yano, K., Curvature and Betti Numbers, Princeton University Press (1953), Annals of Mathematical Studies

[5] Boskoff, W. G., Bărcănescu, Ş. and Bobe, A., On the non-generic Tzitzeica-Johnson's Configuration, Analele Ştiin. Univ. Ovidius Constanţa, 20 (2012), No.2, 21-26.

[6] Boskoff, W. G. and Horja, P., The characterization of some spectral Barbilian spaces using the Tzitzeica construction, Stud. Cercet. Mat., 46 (1994), No. 5, 503-514

[7] Boskoff, W. G. and Suceavă, B. D., Barbilian spaces: The history of a geometric idea, Historia Math., 34 (2007), 221-224

[8] Cartan, É., Les espaces riemanniens symétriques, Verh. Internat. Math. Kongresses Zürich, vol. I, (1932), $152-161$

[9] Cartan, É., Lettres d'É. Cartan à G. Tziţzeica, A., Pantazi et Vrănceanu, G., Hommage de l'Acad. République Socialiste de Roumanie, à l'occasion du centennaire de sa naissance, Editura Acad. R. S. Roumanie, 1975, pp. 83-116

[10] Chen, B.-Y., My Education in Differential Geometry and My Indebtedness, in the volume edited by Joeri Van der Veken et. a. Contemporary Mathematics Series, American Mathematical Society (to appear)

[11] Chen, B.-Y. and Yano, K., On submanifolds of submanifolds of a Riemannian manifold, J. Math. Soc. Japan, 23 (1971), 548-554

[12] Chen, B.-Y. and Yano, K., Minimal submanifolds of a higher dimensional sphere, Tensor (N.S.), 22 (1971), 369-373

[13] Chen, B.-Y. and Yano, K., Integral formulas for submanifolds and their applications, J. Differential Geometry, 5 (1972), 467-477

[14] Chen, B.-Y. and Yano, K., Pseudo umbilical submanifolds in a Riemannian manifold of constant curvature, Differential geometry in honor of Kentaro Yano, (1972), 61-71. Kinokuniya, Tokyo

[15] Chen, B.-Y. and Yano, K., Hypersurfaces of a conformally flat space, Tensor (N.S.), 26 (1972), 318-322

[16] Chen, B.-Y. and Yano, K., Special quasi-umbilical hypersurfaces and locus of spheres, Atti Accad. Naz. Lincei Rend. Cl. Sci. Fis. Mat. Natur., 53 (1972), 255-260

[17] Chen, B.-Y. and Yano, K., Sous-variétés localement conformes à un espace euclidien, C. R. Acad. Sci. Paris Math., 275 (1972), 123-125

[18] Chen, B.-Y. and Yano, K., Conformally flat spaces of codimension 2 in a Euclidean space, Canad. J. Math., 25 (1973), 1170-1173

[19] Chen, B.-Y. and Yano, K., Special conformally flat spaces and canal hypersurfaces, Tohoku Math. J., 25 (1973), 177-184

[20] Chen, B.-Y. and Yano, K., Umbilical submanifolds with respect to a nonparallel normal direction, J. Differential Geometry, 8 (1973), 589-597

[21] Chen, B.-Y. and Yano, K., Submanifolds umbilical with respect to a quasi-parallel normal direction, Tensor (N.S.), 27 (1973), 41-44

[22] Chen, B.-Y. and Yano, K., Submanifolds umbilical with respect to a non-parallel normal subbundle, Kodai Math. Sem. Rep., 25 (1973), 289-296

[23] Chen, B.-Y. and Yano, K., Pseudo-umbilical submanifolds of codimension 3 with constant mean curvature, Kodai Math. Sem. Rep., 25 (1973), 490-501

[24] Chen, B.-Y. and Yano, K., Manifolds with vanishing Weyl or Bochner curvature tensor, J. Math. Soc. Japan, 27 (1975), 106-112

[25] Chen, B.-Y.,and Yano, K., On the theory of normal variations, J. Differential Geom., 13 (1975), 1-10

[26] Kobayashi, Sh., Differential Geometry of Curves and Surfaces, Translated from the Japanese by Eriko Shinozaki Nagumo and Makiko Sumi Tanaka, Springer Undergraduate Mathematics Series, 2019, Springer-Verlag

[27] Marques, F. C. and Neves, A., Min-max theory and the Willmore conjecture, Annals of Mathematics, 179 (2014), 683-782

[28] Obata, M., Selected Papers of Kentaro Yano, Volume 70, North Holland, 1982

[29] O'Connor, J. J. and Robertson, E. F., Kentaro Yano, MacTutor Biography, 2006, https://mathshistory.standrews.ac.uk/Biographies/Yano/

[30] Pambuccian, V. and Zamfirescu, T., Paolo Pizzetti: The forgotten originator oftriangle comparison geometry, Historia Math., 38 (2011), 415-422

[31] Toponogov, V. A., Riemann spaces with curvature bounded below (Russian), Uspehi Mat. Nauk, 14 1959, No. 1 (85), 87-130

[32] Verstraelen, L., Personal communication, (2013)

[33] Willmore, T. J., Note on embedded surfaces, An. Şti. Univ. “Al. I. Cuza” Iaşi, Secţ. I a Mat. (N.S.) B., (1965), 493-496

[34] Yano, K., Les espaces à connexion projective et la géométrie projective des "path", Thèses de l'entre-deux-guerres, No. 207 (1938) , 76 p. Digitized at http:/ / www.numdam.org/ 
[35] Yano, K., Les espaces à connexion projective et la géométrie projective des "path", Analele Ştiinţifice ale Universităţii "Al. I. Cuza" din Iaşi, vol. 24 (1938), pp. 395-464

[36] Yano, K., Sur la théorie des espaces à connexion conforme, Doctoral thesis (1939)

[37] Yano, K., Groups of Transformations in Generalized Spaces, Akademeia Press, Tokyo (1949)

[38] Yano, K., Differential geometry on complex and almost complex spaces, Macmillan, New York (1965)

[39] Yano, K., Integral formulas in Riemannian Geometry, Marcel Dekker, New York ( 1970)

[40] Yano, K., Houh, C. S. and Chen, B.-Y., Intrinsic characterization of certain conformally flat spaces, Kodai Math. Sem. Rep., 25, 357-361

[41] Yano, K. and Kon, M., Structures on manifolds, Series in Pure Mathematics, Vol. 3. (1984), Singapore: World Scientific. Distr. by John Wiley \& Sons Ltd

DEPARTMENT OF MATHEMATICS

CALIFORNIA STATE UNIVERSity, FULlERTON

800 N. State College Blvd., 156 MCCARThy Hall

FULLERTON, CA 92831-6850, U.S.A.

Email address: bsuceava@fullerton. edu 